\title{
An Entropy Testing Model Research on the Quality of Internal Control and Accounting Conservatism: Empirical Evidence from the Financial Companies of China from 2007 to 2011
}

\author{
Zongrun Wang, ${ }^{1}$ Yan Chen, ${ }^{1}$ Yanju Zhou, ${ }^{1}$ and Yanbo Jin ${ }^{2}$ \\ ${ }^{1}$ School of Business, Central South University, Changsha 410083, China \\ ${ }^{2}$ Department of Finance, Real Estate, and Insurance, California State University, Northridge, CA 91330, USA
}

Correspondence should be addressed to Zongrun Wang; zrwang0209@gmail.com

Received 16 December 2013; Accepted 27 January 2014; Published 6 March 2014

Academic Editor: Jianping Li

Copyright (C) 2014 Zongrun Wang et al. This is an open access article distributed under the Creative Commons Attribution License, which permits unrestricted use, distribution, and reproduction in any medium, provided the original work is properly cited.

\begin{abstract}
We set information disclosure of internal control as a starting point to explore the relationship between the quality of internal control and accounting conservatism, and then adopt the entropy testing model to calculate the index of the internal control quality with the sample data of Chinese listed companies in financial industry from 2007-2011. Regression results show that earnings conservatism exists. The stronger the internal control is, the higher the accounting conservatism can be. Companies which have enhanced their internal control are more conservative, and these results make no difference with other industries.
\end{abstract}

\section{Introduction}

The financial crisis in 2008 , followed by the debt crisis in Europe and the U.S., leading to the rebuild of the balance sheet and global economy's boundless recessions, is enabling people to reassess the importance of risk management in financial institutions. Internal control and risk management are closely related. A sound internal control system can effectively promote the quality of financial reports and improve the level of corporate governance. Accounting conservatism, a measure of accounting earnings quality, is one of the most important qualities of financial reporting and also an important guarantee for the stable development of enterprises. Watts [1] is the first man who carries out a systemic study on accounting conservatism. He confirms that accounting conservatism can reduce firms' debt cost and can mitigate bondholder-shareholder conflicts over dividend policy.

Since 1997, China has released a series of guidelines and regulations for listed financial institutions' internal control which contributes to the internal control construction and information transparency in the high risk industry, as shown in Table 1. However, according to the Internal Control SelfAssessment Survey made by the Shanghai Stock Exchange in 2011, the information disclosure of internal control of Chinese listed companies is far from satisfaction. For instance, the redundant information is overloaded; the criteria for internal control deficiencies are unknown; the disclosure is inadequate, and so forth. We find that up to 2011, only five financial institutions, during the reporting period, including one in brokerage, two in investment banking, and another two in information systems, have disclosed their defects existing in internal control of enterprise. Others have always kept silent on the major deficiencies while just admitting the minor ones or made the disclosure of their internal control deficiencies an action of mere formality or simply used the words like "need improvement," "need to take further measures," or "inadequate" and so on instead of presenting a detailed description of the internal control deficiencies.

The problems in information disclosure of internal control described above makes it a difficult job in empirical researches to quantify the quality of internal control and explore the relationship between internal control and accounting conservatism. 
TABLE 1: Regulations on internal control of the financial industry in China.

\begin{tabular}{|c|c|c|}
\hline Year & Promulgation institution & Titles \\
\hline 1997 & People’s Bank of China & Guiding principles that strengthen the internal control of financial institutions \\
\hline 2000 & $\begin{array}{l}\text { China Securities Regulatory } \\
\text { Commission (Hereinafter } \\
\text { referred to as CSRC) }\end{array}$ & $\begin{array}{l}\text { The compilation rules for public offering securities companies to disclose } \\
\text { information, number } 1,3 \text {, and } 5\end{array}$ \\
\hline 2002 & People's Bank of China & Guidelines for the internal control of commercial banks \\
\hline 2002 & CSRC & $\begin{array}{l}\text { Guiding opinions on the internal control of securities investment fund management } \\
\text { companies }\end{array}$ \\
\hline 2003 & CSRC & Guidelines for the internal control of securities company \\
\hline 2004 & $\begin{array}{l}\text { China Insurance Regulatory } \\
\text { Commission (Hereinafter } \\
\text { referred to as CIRC) }\end{array}$ & Guidelines for internal control of insurance intermediary institutions \\
\hline 2006 & CIRC & Evaluation methods on internal control of life insurance company \\
\hline 2007 & $\begin{array}{l}\text { China Banking Regulatory } \\
\text { Commission (Hereinafter } \\
\text { referred to as CBRC) }\end{array}$ & Guidelines for the internal control of commercial banks \\
\hline 2008 & $\begin{array}{l}\text { The Ministry of Finance, the } \\
\text { Audit Commission, CBRC, } \\
\text { CIRC, CSRC }\end{array}$ & Fundamental standards of corporate internal control \\
\hline 2009 & $\begin{array}{l}\text { State-owned Assets Supervision } \\
\text { and Administration Commission }\end{array}$ & $\begin{array}{l}\text { Notice on further strengthening the supervision of financial derivative business of } \\
\text { governmental enterprises }\end{array}$ \\
\hline 2010 & $\begin{array}{l}\text { The Ministry of Finance, the } \\
\text { Audit Commission, CBRC, } \\
\text { CIRC, CSRC }\end{array}$ & $\begin{array}{l}\text { Application guidelines, audit guidelines, and evaluation guidelines for corporate } \\
\text { internal control }\end{array}$ \\
\hline 2012 & The Ministry of finance & $\begin{array}{l}\text { Number } 1 \text { of the notice on Accounting (2012) and number } 3 \text { that explain problems } \\
\text { related to implementation of the internal control standard system }\end{array}$ \\
\hline
\end{tabular}

Comparing the researches at home and abroad, we find that the empirical researches overseas mainly focus on defects of enterprise's internal control and directly use the disclosed material weaknesses to stand for their internal control quality [2-6]. However, this practice finds it hard to prevail in China, because companies always have enough motivations to cover their shortcomings when punishment is inadequate. To measure the level of the internal control quality, domestic researchers are continuously defining the variables of different forms of internal control quality, most of which measure the quality of internal control against the occurrence of certain events, including Zhang [7], Qi et al. [8], and Kong [9], who find that the cost of debt is higher when a company has major internal control deficiencies.

Goh and Li [2] find that the existence of material weaknesses can represent the level of its internal control quality, and there is a positive relation between internal control quality and accounting conservatism, and that companies that disclose material weaknesses and subsequently remedy those weaknesses can exhibit stronger conservatism than companies that never do anything to improve the situation. Munsif et al. [3] examined the audit fees and found that companies differ from one another in audit fees when they choose to or not remedy the previously disclosed material weaknesses in internal control. The remediate companies have lower audit fees compared with the ones that are not. Givoly et al. [10] found that public equity companies report more conservatively than the private equity counterparts, and, at the same time, the former have a greater propensity to manage earnings.

In recent years, the entropy method is considered as a more effective method for building the index of internal control information disclosure quality (see [11, 12]). This method not only has an advantage in comprehensiveness, objectivity, and reliability, but also reflects the background of institutional changes and effectively reflects the differences between individuals.

In this paper, we use the cross section sample data of Chinese listed companies in the financial industry from 2007-2011 to examine the relationship between quality of internal control and accounting conservatism.

Our first contribution is that we adopt the entropy method to quantify the quality of internal control. Meanwhile, because of the peculiarities of financial industry, related studies often exclude the financial companies. Yet this paper examines whether the relationship between the quality of internal control and accounting conservatism in financial industry differs from that in other sectors. What is more, compared with other industries, is that the regulatory authorities are stricter with financial industry in disclosure requirements of internal control and the period between 2007 and 2011 is exactly the voluntary disclosure phase for companies in China to disclose their self-assessment reports and assurance reports in internal control. So, the second contribution is that our study on the voluntary disclosure phase for financial listed companies helps to provide a significant 
reference for the comprehensive application in mandatory disclosure phase for all listed companies in China.

Our paper is organized as follows. Section 2 gives the hypothesis development; Section 3 describes the research design; Section 4 discusses the empirical results; Section 5 concludes with main findings.

\section{Hypothesis Development}

The discussions for the relationship between internal control and conservatism have long been hot. Firstly, According to the explanation of signal transfer point in information economics, strong internal control can be seen as a positive signal that is delivered to investors. Armstrong et al. [13] found that better internal control systems enable companies to provide more reliable financial statements, and the transparency in financial reporting can make up for the information asymmetry and reduce agency conflicts among stakeholders. Secondly, weaker internal control may lead to some of the unwitting mistakes and reduce the level of enterprises' accounting conservatism. Ashbaugh-Skaife et al. [14] thought that such internal control problems as lack of institutional norms, inadequate staff training, and so on are likely to cause these mistakes. Thirdly, accompanied by weaker internal controls, problems like management deficiencies, inadequate personnel qualification, deficiencies of institutional norms, and so forth can easily lead to untimely recognition of losses and can lower accounting conservatism. Meanwhile, stable operation makes significant sense to financial companies. In practice, due to inadequate internal control, various kinds of incidents in violation of rules and regulations are not uncommon in financial industry. So the inference that to improve the quality of internal control can reduce the incidence of noncompliance seems easy to understand. On the other hand, there are scholars who have challenged the view that perfect internal control system can promote conservatism. Levitt [15] and Penman and Zhang [16] argue that conservatism can increase earnings management, which can worsen agency conflicts and exacerbate information asymmetry. Jensen [17] thinks that the accounting conservatism principle requires companies to promptly confirm the recognition of loss and postpone the recognition of income, which can easily lead to the unfair financial reporting. Given these, the idea that effective internal control system can promote the accounting conservatism is untenable. In China, accounting conservatism has once been blamed as a tool for manipulating accounting numbers and has been prohibited in practice for nearly 40 years since 1949 . Based on the above theoretical analysis, we propose the following assumptions as a starting point to look into the issue.

(H1) Accounting conservatism exists in Chinese listed financial companies.

(H2) There is positive correlation between the quality of internal control and accounting conservatism in Chinese financial listed companies.

(H3) Companies which have enhanced their internal control quality are more conservative than those which fail to do so.

\section{Research Design}

3.1. Model Design and Variable Definitions. Zhang et al. [18] empirically studied the differences in the selection of different measurement methods of accounting conservatism from the angles of relevance and reliability, respectively. Based on their research, we adopt the accrual-based loss recognition measurement and the persistence of earnings changes measurement to study the quality of internal control and accounting conservatism in financial industry. The accrualbased loss recognition measurement is highly reliable, which can be used simultaneously with the persistence of earnings changes measurement because they are negatively or weakly related to each other, and we can also make the results reliable and robust to a certain extent by using the two methods.

3.1.1. Accrual-Based Loss Recognition Model. This model, based on correlation between accruals and the contemporaneous cash flows, is designed by Ball and Shivakumar [19]. It takes the cash flow in operating activities as a substitution variable for "good news" and "bad news", and tells the differences in timeliness by which gains and losses are recognized. Referring to Goh and $\mathrm{Li}$ [2], we include the index of the internal control quality (ICQ) and the cross term of ICQ and select separation of two rights, the asset-liability ratio and the asset size as control variables (Table 2 ). The extended accrual-based loss recognition model is as follows:

$$
\begin{aligned}
\text { ACCRUAL }= & \gamma_{0}+\gamma_{1} \mathrm{DCFO}+\gamma_{2} \mathrm{CFO}+\gamma_{3} \mathrm{DCFO} * \mathrm{CFO} \\
& +\gamma_{4} \mathrm{ICQ}+\gamma_{5} \mathrm{ICQ} * \mathrm{DCFO} \\
& +\gamma_{6} \mathrm{ICQ} * \mathrm{CFO}+\gamma_{7} \mathrm{ICQ} * \mathrm{DCFO} * \mathrm{CFO} \\
& +\gamma_{8} \mathrm{STR}+\gamma_{9} \mathrm{LEV}+\gamma_{10} \mathrm{SIZE}+\varepsilon_{t} .
\end{aligned}
$$

3.1.2. Persistence of Earnings Changes Model. This model is proposed by Basu [20], who gives the definition for accounting conservatism as managers require more rigorous evidence in loss recognition than that in gains recognition. He also believes that compared with the booming periods, companies in the recession period show lower sustainability of income and that from the time-series perspective, the bad news appear as a transitory shock in the earnings process while the effects of good news will be spread over the earnings in the future as the anticipated gains are realized. The extended persistence of earnings changes model that includes ICQ and the control variables is as follows:

$$
\begin{aligned}
\Delta \mathrm{NI}_{t}= & \alpha_{0}+\alpha_{1} \mathrm{D} \Delta \mathrm{NI}_{t-1}+\alpha_{2} \Delta \mathrm{NI}_{t-1} \\
& +\alpha_{3} \mathrm{D} \Delta \mathrm{NI}_{t-1} * \Delta \mathrm{NI}_{t-1}+\alpha_{4} \mathrm{ICQ}+\alpha_{5} \mathrm{ICQ} * \mathrm{D} \Delta \mathrm{NI}_{t-1} \\
& +\alpha_{6} \mathrm{ICQ} * \Delta \mathrm{NI}_{t-1}+\alpha_{7} \mathrm{ICQ} * \mathrm{D} \Delta \mathrm{NI}_{t-1} * \Delta \mathrm{NI}_{t-1} \\
& +\gamma_{8} \mathrm{STR}+\gamma_{9} \mathrm{LEV}+\gamma_{10} \mathrm{SIZE}+\varepsilon_{t} .
\end{aligned}
$$

In the accrual-based loss recognition model, since the variable ACCRUAL is in the opposite direction with 
TABLE 2: Variable definitions ${ }^{1}$.

\begin{tabular}{|c|c|}
\hline Variable & Variable definitions \\
\hline ACCRUAL & $\begin{array}{l}\text { Net income before extraordinary items minus operating cash flows for firm } i \text { in fiscal year } t \text { deflated by } \\
\text { beginning-of-year total assets }\end{array}$ \\
\hline $\mathrm{CFO}$ & Operating cash flows at the end of the fiscal year deflated by beginning-of-year total assets \\
\hline DCFO & If $\mathrm{CFO} \geq 0$, DCFO equals 0,1 otherwise \\
\hline$\Delta \mathrm{NI}_{t}$ & Change in net income before extraordinary items for firm $i$ in fiscal year $t$ deflated by beginning-of-year total assets \\
\hline $\mathrm{D} \Delta \mathrm{NI}_{t-1}$ & If $\Delta \mathrm{NI}_{t-1} \geq 0, \mathrm{D} \Delta \mathrm{NI}_{t-1}$ equals 0,1 otherwise \\
\hline ICQ & Calculated by the entropy method, and the smaller the ICQ is, the better the quality of internal control will be \\
\hline HLIC & If the quality of internal control gets better this year than the year before, then HLIC equals 0,1 otherwise \\
\hline STR & Control variable: the difference between control power and the proprietary rights \\
\hline LEV & Control variable: the asset-liability ratio \\
\hline SIZE & Control variable: natural log of the total assets at the end of the fiscal year $t$ \\
\hline
\end{tabular}

${ }^{1}$ If there is no footnote for the variable, it all indicates that the value refers to the current year.

the annual operating cash flow CFO, the coefficient of $\gamma_{2}$ is negative. The coefficient of $\gamma_{3}$ reflects the time difference in recognizing the negative cash flow and the positive cash flow. As we know, the negative cash flow changes in the same direction with ACCRUAL, so if earnings conservatism exists in the listed financial companies, the coefficient of $\gamma_{3}$ is predicted to be positive. Similarly, if weak internal control systems result in lower accounting conservatism, then the accruals will not so timely recognize the negative changes of cash flows; therefore, we forecast $\gamma_{7}$ to be negative.

In the persistence of earnings changes model, the coefficient of $\alpha_{2}$ measures how much the surplus recognizes good news, and $\alpha_{3}$ reflects the earnings reversal incremental speed of loss against earnings. Therefore, the existence of accounting conservatism means that the coefficient of $\alpha_{3}$ should be significantly negative; that is to say, the bad news was recognized more timely than the good ones. Similarly, if the coefficient of $\alpha_{7}$ is positive, it means that the companies with weaker internal control are less conservative compared to the ones that have stronger internal control system, which can verify the hypothesis II.

To test whether firms which have improved their quality of internal control can exhibit different levels of conservatism from the ones that have not, we introduce the dummy variable HLIC. If the quality of internal control gets better this year than the year before, then HLIC equals 1 , otherwise 0 . Replace the variable ICQ with HLIC in model (1) and the model (2). We get the following two other models. If $(\mathrm{H} 3)$ is tenable, then the coefficients of HLIC $* \mathrm{DCFO} * \mathrm{CFO}$ and HLIC $* \mathrm{D} \Delta \mathrm{NI}_{t-1} *$ $\Delta \mathrm{NI}_{t-1}$ should be negative and positive, respectively,

$$
\begin{aligned}
\text { ACCRUAL }= & \gamma_{0}+\gamma_{1} \mathrm{DCFO}+\gamma_{2} \mathrm{CFO}+\gamma_{3} \mathrm{DCFO} * \mathrm{CFO} \\
& +\gamma_{4} \mathrm{HLIC}+\gamma_{5} \mathrm{HLIC} * \mathrm{DCFO} \\
& +\gamma_{6} \mathrm{HLIC} * \mathrm{CFO}+\gamma_{7} \mathrm{HLIC} * \mathrm{DCFO} * \mathrm{CFO} \\
& +\gamma_{8} \mathrm{STR}+\gamma_{9} \mathrm{LEV}+\gamma_{10} \mathrm{SIZE}+\varepsilon_{t},
\end{aligned}
$$

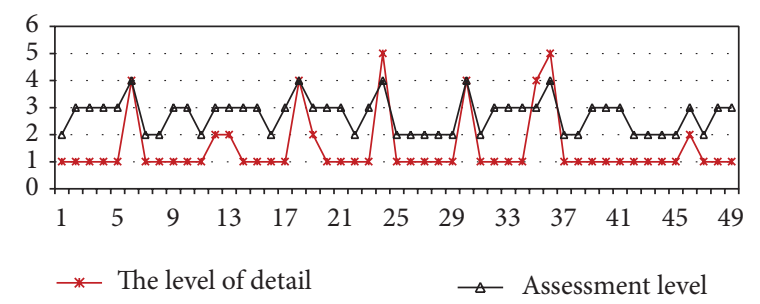

FIGURE 1: Contrast between the Level of detailed evaluation for information disclosure of internal control and the information disclosure evaluation results from SZSE (the information disclosure evaluation results from Shenzhen Stock Exchange are divided into four grades, which are $\mathrm{A}, \mathrm{B}, \mathrm{C}$, and $\mathrm{D}$, respectively; we have done a data processing, making "A" equal 1 , "B" equal 2 , "C" equal 3 , and "D" equal 4 for the benefit of comparing).

$$
\begin{aligned}
\Delta \mathrm{NI}_{t}= & \alpha_{0}+\alpha_{1} \mathrm{D} \Delta \mathrm{NI}_{t-1}+\alpha_{2} \Delta \mathrm{NI}_{t-1} \\
& +\alpha_{3} \mathrm{D} \Delta \mathrm{NI}_{t-1} * \Delta \mathrm{NI}_{t-1}+\alpha_{4} \mathrm{HLIC} \\
& +\alpha_{5} \mathrm{HLIC} * \mathrm{D} \Delta \mathrm{NI}_{t-1}+\alpha_{6} \mathrm{HLIC} * \Delta \mathrm{NI}_{t-1} \\
& +\alpha_{7} \mathrm{HLIC} * \mathrm{D} \Delta \mathrm{NI}_{t-1} * \Delta \mathrm{NI}_{t-1} \\
& +\gamma_{8} \mathrm{STR}+\gamma_{9} \mathrm{LEV}+\gamma_{10} \mathrm{SIZE}+\varepsilon_{t} .
\end{aligned}
$$

3.2. The Calculation of the Index of the Internal Control Quality Based on Entropy Testing Model. We select the factors that have significant impact on the quality of internal control to build the indicator system (Table 3 ), which is used to calculate the index of the internal control quality (ICQ) in financial industry by the entropy testing model.

Especially, in Figure 1, we make a comparison between our assessment of the level of detail for internal control information and the Shenzhen Stock Exchange information disclosure evaluation results which can be inquired from the website of Shenzhen Stock Exchange. The results show that our assessment basically consists with the evaluation of SZSE, which indicates our evaluation has its rationality. The specific 
TABLE 3: Indicator system for the index of the internal control quality ${ }^{2}$.

Variables
Internal control deficiencies
Internal control
self-assessment report
Internal control assurance
reports
Types of the assurance
reports

Auditor

Two-position in one person

The level of detail for internal control information

The proportion of independent directors
Variable definitions

"not exist" = 1, "common defects" = 3, "material weaknesses (for example, punished by the authorities etc.)" $=5$;

"exist" $=1$, "not exist" $=5$, if the annual report says that the Report has been disclosed and yet in fact the opposite is true, then it shall be regarded as no disclosure;

"exist" = 1 , "not exist" $=5$, if the annual report says that the Report has been disclosed and yet in fact the opposite is true, then it shall be regarded as no disclosure;

"reasonable assurance" $=1$, "limited assurance" $=3$, "low assurance or no assurance" = 5;

"the internal control assurance report is audited by one of the big four accounting firms" =1, "the internal control assurance report is not audited by one of the big four accounting firms, but the financial report is" $=3$, "none of the reports are audited by the big four accounting firms" $=5$; "not exist" =1, "vice chairman and general manager are the same people" = 3, "chairman and general manager are the same people" $=5$;

It is divided into five levels from 1 to 5 ; the smaller the level is, the more detailed it would be;

$">=0.4 "=1, ">=0.3$ and $<0.4 "=3, "<0.3 "=5$.

${ }^{2}$ (a) The types of internal control assurance report: Given the extent that the internal control assurance report guarantees, there's a big difference in assurance targets, evidence collection, requirements of the assurance reports, responsibility of accountingfirms and so on Liu [21]. This article specifies three situations: when firms provide internal control audit reports, it is seen as reasonable assurance; providing other types of internal control assurance reports is seen as limited assurance, and providing no internal control assurance reports or only the examination report of internal control from its sponsors is seen as no or low guarantee. (b) The levels of detail for internal control information: According to Yang and Wang [22], we divide the level of detail for internal control information into five levels.

steps to calculate the index of the internal control quality by entropy method are as follows.

(1) Create the original evaluation matrix, wherein $a_{i j}$ represents the value for the $i$ sample firm on the $j$ factor

$$
A=\left(\begin{array}{cccc}
a_{11} & a_{12} & \cdots & a_{1 j} \\
a_{21} & a_{22} & \cdots & a_{2 j} \\
\cdots & \cdots & \vdots & \cdots \\
a_{i 1} & a_{i 2} & \cdots & a_{i j}
\end{array}\right)
$$

(2) Calculate the dimensionless matrix. The different indicator often has the different dimension and the dimensional unit; to eliminate the commensurability coming from this difference, we make dimensionless treatment on $\alpha_{i j}$ and get the matrix $B=\left(b_{i j}\right)_{m \times n}$

$b_{i j}= \begin{cases}\frac{\min _{j} a_{i j}}{a_{i j}}, & a_{i j} \in I_{1}, I_{1} \text { is a positive indicator } \\ \frac{a_{i j}}{\max _{j} a_{i j}}, & a_{i j} \in I_{2}, I_{2} \text { is a negative indicator. }\end{cases}$

(3) Calculate the indicator weight $p_{i j}$ for $b_{i j}$

$$
p_{i j}=\frac{b_{i j}}{\sum_{i=1}^{m} b_{i j}} \text {. }
$$

(4) Compute the entropy value $H_{j}$ and its entropy weight for indicator $j$

$$
\begin{gathered}
H_{j}=-k \sum_{i=1}^{m} p_{i j} \operatorname{In} p_{i j} \quad(j=1,2, \ldots, n), \\
w_{j}=\frac{1-H_{j}}{n-\sum_{j=1}^{n} H_{j}} .
\end{gathered}
$$

Wherein $K=1 /$ In $m$, and suppose that if $p_{i j}=0$, $p_{i j}$ In $p_{i j}=0$, the bigger $H_{j}$ is, the more information the $m$ scheme contains in the $j$ indicator; otherwise, the less information it contains.

(5) Calculate the index of the internal control quality (ICQ) for firm $i$

$$
\mathrm{ICQ}_{i}=\sum_{j=1}^{4} w_{j} a_{i j}, \quad(i=1,2, \ldots, n) .
$$

\subsection{Sample Selection and Descriptive Statistics}

3.3.1. Data Sources and Sample Selection. This paper selects the data of 2007-2011 Chinese financial listed companies as samples. By the end of 2011, China has had 40 financial listed companies, including sixteen banks, eighteen securities companies, four insurance companies, and two trust and investment companies. By excluding the missing data samples and data of the years in which the sample companies have not listed, we get 103 cross-sectional samples for the accrualbased loss recognition model and 93 cross-sectional samples 
TABLE 4: Statistical Table of the internal control information disclosure in sample firms ${ }^{4}$.

\begin{tabular}{|c|c|c|c|c|}
\hline Variables & Variable value & 1 & 3 & 5 \\
\hline \multirow{5}{*}{ Internal control deficiencies } & 2011 & $79.49 \%$ & $17.95 \%$ & $2.56 \%$ \\
\hline & 2010 & $28.57 \%$ & $57.14 \%$ & $14.29 \%$ \\
\hline & 2009 & $27.59 \%$ & $55.17 \%$ & $17.24 \%$ \\
\hline & 2008 & $26.92 \%$ & $61.54 \%$ & $11.54 \%$ \\
\hline & 2007 & $36.00 \%$ & $44.00 \%$ & $20.00 \%$ \\
\hline \multirow{5}{*}{ Internal control self-assessment report } & 2011 & $100.00 \%$ & - & $0.00 \%$ \\
\hline & 2010 & $100.00 \%$ & - & $0.00 \%$ \\
\hline & 2009 & $96.55 \%$ & - & $3.45 \%$ \\
\hline & 2008 & $100.00 \%$ & - & $0.00 \%$ \\
\hline & 2007 & $64.00 \%$ & - & $36.00 \%$ \\
\hline \multirow{5}{*}{ Types of the assurancereports } & 2011 & $56.41 \%$ & $38.46 \%$ & $5.13 \%$ \\
\hline & 2010 & $0.00 \%$ & $88.57 \%$ & $11.43 \%$ \\
\hline & 2009 & $0.00 \%$ & $86.21 \%$ & $13.79 \%$ \\
\hline & 2008 & $0.00 \%$ & $80.77 \%$ & $19.23 \%$ \\
\hline & 2007 & $0.00 \%$ & $60.00 \%$ & $40.00 \%$ \\
\hline \multirow{5}{*}{ Auditor } & 2011 & $58.97 \%$ & $2.56 \%$ & $38.46 \%$ \\
\hline & 2010 & $57.14 \%$ & $0.00 \%$ & $42.86 \%$ \\
\hline & 2009 & $51.72 \%$ & $0.00 \%$ & $48.28 \%$ \\
\hline & 2008 & $53.85 \%$ & $0.00 \%$ & $46.15 \%$ \\
\hline & 2007 & $52.00 \%$ & $0.00 \%$ & $48.00 \%$ \\
\hline \multirow{5}{*}{ Two-position in one person } & 2011 & $76.92 \%$ & $20.51 \%$ & $2.56 \%$ \\
\hline & 2010 & $71.43 \%$ & $25.71 \%$ & $2.86 \%$ \\
\hline & 2009 & $75.86 \%$ & $24.14 \%$ & $0.00 \%$ \\
\hline & 2008 & $73.08 \%$ & $26.92 \%$ & $0.00 \%$ \\
\hline & 2007 & $68.00 \%$ & $32.00 \%$ & $0.00 \%$ \\
\hline \multirow{5}{*}{ The proportion of independent directors } & 2011 & $15.38 \%$ & $82.05 \%$ & $2.56 \%$ \\
\hline & 2010 & $5.71 \%$ & $88.57 \%$ & $5.71 \%$ \\
\hline & 2009 & $17.24 \%$ & $75.86 \%$ & $6.90 \%$ \\
\hline & 2008 & $15.38 \%$ & $73.08 \%$ & $11.54 \%$ \\
\hline & 2007 & $16.00 \%$ & $64.00 \%$ & $20.00 \%$ \\
\hline
\end{tabular}

${ }^{4}$ The specific meaning of variable values can be referred to in Table 2 .

for the persistence of earnings changes model; the sample size can meet the basic requirements of regression. The information of internal control is collected manually by reading the annual reports and looking for the information from Shenzhen Stock Exchange and Shanghai Stock Exchange Web sites and other related web sites, the financial data are from CSMAR database.

3.3.2. Descriptive Statistics. Table 4 presents the descriptive statistics for the information of internal control in financial listed companies, where we can see a trend that companies that disclose their internal control deficiencies are decreasing in numbers. In 2007, the Guidelines that Shanghai Stock Exchange and Shenzhen Stock Exchange, respectively, issued were put into formal implementation, and the proportion of companies which disclose their internal control weaknesses in 2007 is relatively bigger than the other years, with $20 \%$ disclosing material defects, and $44 \%$ general defects. From 2008 to 2010 , the proportion was going down in the disclosure of material defects but going up in general defects. In 2011, the proportions for the two kinds of defects were both reduced significantly. To summarize, from the number of the disclosed internal control defects, we can see a decreasing trend, perhaps this is due to the improvement of internal control itself, but we still cannot exclude the possibility that this may be the result of a psychological game that financial firms play with regulators. In terms of the disclosure content, only a few companies directly say that they have internal control deficiencies, most companies use a more gentle and indirect wordage to describe the situation, like the need for improvement, presence of shortcomings, and so on. In 2011, $56.41 \%$ of internal control assurance reports were audited by the accounting firms, whereas no internal control audit reports were disclosed before by any of the companies. It can be seen as a signal that the financial companies are trying to improve their internal control system in order to accommodate the upcoming mandatory disclosure stage. What is more is that over half of the financial listed companies have chosen the Big Four accounting firms to do their auditing activities, which can be seen as increasing confidence in the reliability 
TABLE 5: Pearson correlation coefficients among the main variables ${ }^{5}$.

\begin{tabular}{|c|c|c|c|c|c|c|}
\hline Variables & $\Delta \mathrm{NI}_{t}$ & $\Delta \mathrm{NI}_{t-1}$ & $\mathrm{D} \Delta \mathrm{NI}_{t-1}$ & ICQ & HLIC & \\
\hline ACCRUAL & 1 & -0.041 & $0.211^{* *}$ & 0.131 & 0.067 & $\Delta \mathrm{NI}_{t}$ \\
\hline $\mathrm{CFO}$ & $-0.948^{* * *}$ & 1 & -0.114 & 0.053 & -0.113 & $\Delta \mathrm{NI}_{t-1}$ \\
\hline DCFO & $0.220^{* * *}$ & $-0.211^{* *}$ & 1 & 0.1 & -0.056 & $\mathrm{D} \Delta \mathrm{NI}_{t-1}$ \\
\hline ICQ & -0.03 & 0.072 & 0.008 & 1 & $-0.224^{* * *}$ & ICQ \\
\hline \multirow[t]{2}{*}{ HLIC } & 0.1 & 1.22 & $-0.209^{* *}$ & $-0.244^{* * *}$ & 1 & HLIC \\
\hline & ACCRUAL & $\mathrm{CFO}$ & DCFO & ICQ & HLIC & \\
\hline
\end{tabular}

*,**,*** Denote significant differences at the 10 percent, 5 percent, and 1 percent levels, respectively, based on two-tailed tests.

${ }^{5}$ The Pearson correlation coefficients in left bottom are from accrual-based loss recognition model and the right bottom ones from the persistence of earnings changes model.

TABLE 6: Regression results of the panel data models with ICQ.

\begin{tabular}{|c|c|c|c|}
\hline \multicolumn{2}{|c|}{ Model (1) } & \multicolumn{2}{|c|}{ Model (2) } \\
\hline Independent Variables & Coefficient & Independent variables & Coefficient \\
\hline$C$ & $-0.002(-0.106)$ & $C$ & $18.781^{* *}(2.595)$ \\
\hline DCFO & $0.031^{*}(1.906)$ & $\Delta \mathrm{NI}_{t-1}$ & $-1.789^{* *}(-2.350)$ \\
\hline $\mathrm{CFO}$ & $-0.919^{* * *}(-60.315)$ & $\mathrm{D} \Delta \mathrm{NI}_{t-1}$ & $-0.446(-0.555)$ \\
\hline $\mathrm{DCFO} * \mathrm{CFO}$ & $0.544^{* * *}(33.203)$ & $\mathrm{D} \Delta \mathrm{NI}_{t-1} * \Delta \mathrm{NI}_{t-1}$ & $-3.057(-0.441)$ \\
\hline ICQ & $-0.019^{*}(-1.736)$ & ICQ & $-0.599(-0.935)$ \\
\hline $\mathrm{DCFO} * \mathrm{ICQ}$ & $-0.159^{* * *}(-2.714)$ & $\mathrm{D} \Delta \mathrm{NI}_{t-1} * \mathrm{ICQ}$ & $3.758^{* *}(2.078)$ \\
\hline $\mathrm{CFO} * \mathrm{ICQ}$ & $0.182^{* * *}(4.621)$ & $\Delta \mathrm{NI}_{t-1} * \mathrm{ICQ}$ & $-0.791(-0.422)$ \\
\hline $\mathrm{DCFO} * \mathrm{CFO} * \mathrm{ICQ}$ & $-2.926^{* * *}(-63.551)$ & $\mathrm{D} \Delta \mathrm{NI}_{t-1} * \Delta \mathrm{NI}_{t-1} * \mathrm{ICQ}$ & $7.527(0.615)$ \\
\hline STR & $0.105(1.603)$ & STR & $-0.961(-0.498)$ \\
\hline LEV & $-0.082^{* * *}(-3.068)$ & LEV & $3.978^{* *}(2.976)$ \\
\hline SIZE & $0.007^{* * *}(4.822)$ & SIZE & $-1.880^{* *}(-2.939)$ \\
\hline $\operatorname{Adj}_{-} R^{2}$ & 0.852 & Adj_R $R^{2}$ & 0.830 \\
\hline
\end{tabular}

*,**,*** Denote significant differences at the 10 percent, 5 percent, and 1 percent levels.

of their financial reports. As for the duty separation issue, more than $70 \%$ of companies do not have two-position in one person phenomenon, but there is a considerable part of the companies which have the problems that the vice chairman and general manager are the same people or the chairman is also the CEO, and so forth. Meanwhile, the proportion for companies who have less than $1 / 3$ independent directors shows a diminishing trend from 2007 to 2011, indicating that the independence of the board has been enhanced.

Table 5 presents the Pearson correlation statistics of main variables in the two different kinds of models. From the table we can see that, except for the fact that correlation coefficient between CFO and ACCRUAL is bigger than 0.5, other correlation coefficients are all below this level. Given the fact that CFO and ACCRUAL are independent variable and the dependent variable; the high correlation coefficient is reasonable and it has little effect on the regression. In addition, from the correlation coefficient in the table, we can see some important relationship between these variables. The correlation coefficient between CFO and ACCRUAL is significantly negative, and the correlation coefficient between DCFO and ACCRUAL is significantly positive, which can confirm the assumption that the variable ACCRUAL is in the opposite direction with the annual operating cash flow. The correlation coefficient between DCFO and HLIC is -0.209
$(P<0.05)$, which means that if the quality of internal control gets better, then the operating cash flows can be relatively lower. Since the operating cash flows and the ACCRUAL are negatively related, then we can infer that the firm whose internal control gets better has a higher ACCRUAL thus is more conservative.

\section{Panel Data Regression Analysis}

We do the unit root tests for the main variables except the control variables and find that none of variables have unit root but $\mathrm{D} \Delta \mathrm{NI}_{t-1}$, which is integrated of order 1 , and we can see from this result that the panel data is basically stable. In cointegration test, the accrual-based loss recognition model has passed the test, which indicates that there exists a longterm stable equilibrium relationship in this model. We could not do the cointegration test with the persistence of earnings changes model because of the insufficient sample size.

After doing the $F$ test to determine the estimation method of panel data, we come to the conclusion that the accrual-based loss recognition measurement should be a cross-weighted mixed model, and the individual fixed effects model is most suitable for the persistence of earnings changes measurement. The panel data regression results are shown in Tables 6 and 7, and we run models in Table 6 with ICQ, 
TABLE 7: Regression results of the panel data models with HLIC.

\begin{tabular}{|c|c|c|c|}
\hline \multicolumn{2}{|c|}{ Model (3) } & \multicolumn{2}{|c|}{ Model (4) } \\
\hline Independent Variables & Coefficient & Independent variables & Coefficient \\
\hline$C$ & $-0.028(-1.151)$ & $C$ & $16.332^{* * *}(2.760)$ \\
\hline DCFO & $0.004(0.881)$ & $\Delta \mathrm{NI}_{t-1}$ & $-0.854^{*}(-1.912)$ \\
\hline $\mathrm{CFO}$ & $-0.878^{* * *}(-34.090)$ & $\mathrm{D} \Delta \mathrm{NI}_{t-1}$ & $-0.777^{* * *}(-4.768)$ \\
\hline $\mathrm{DCFO} * \mathrm{CFO}$ & $-0.156^{* * *}(-6.019)$ & $\mathrm{D} \Delta \mathrm{NI}_{t-1} * \Delta \mathrm{NI}_{t-1}$ & $-2.422(-0.231)$ \\
\hline HLIC & $-0.008^{* * *}(-2.853)$ & HLIC & $-0.325^{* *}(-2.155)$ \\
\hline $\mathrm{DCFO} * \mathrm{HLIC}$ & $-0.038^{* * *}(-3.570)$ & $\mathrm{D} \Delta \mathrm{NI}_{t-1} * \mathrm{HLIC}$ & $1.016^{* *}(2.068)$ \\
\hline $\mathrm{CFO} * \mathrm{HLIC}$ & $0.101^{* * *}(3.929)$ & $\Delta \mathrm{NI}_{t-1} * \mathrm{HLIC}$ & $-0.735(-0.389)$ \\
\hline $\mathrm{DCFO} * \mathrm{CFO} * \mathrm{HLIC}$ & $-0.824^{* * *}(-31.948)$ & $\mathrm{D} \Delta \mathrm{NI}_{t-1} * \Delta \mathrm{NI}_{t-1} * \mathrm{HLIC}$ & $5.511(0.535)$ \\
\hline STR & $0.060(1.563)$ & STR & $-1.554(-0.398)$ \\
\hline LEV & $-0.036^{* *}(-2.444)$ & LEV & $2.807^{*}(1.943)$ \\
\hline SIZE & $0.005^{* *}(2.601)$ & SIZE & $-1.587^{* * *}(-2.990)$ \\
\hline $\operatorname{Adj} \_^{2}$ & 0.891 & $\operatorname{Adj}_{-} R^{2}$ & 0.887 \\
\hline
\end{tabular}

${ }^{*, * *, * * *}$ Denote significant differences at the 10 percent, 5 percent, and 1 percent level.

and HLIC in Table 7. From the results, we can see that the adjusted $R^{2}$ in all the four models are big enough to demonstrate a good effect and high precision. Based on the previous analysis, we know that if the coefficients of $\mathrm{CFO}$ and $\mathrm{DCFO} * \mathrm{CFO}$ are to be negative and positive, respectively, in the accrual-based loss recognition model, and the coefficient of $\mathrm{D} \Delta \mathrm{NI}_{t-1} * \Delta \mathrm{NI}_{t-1}$ in the persistence of earnings changes model comes to be negative, then the (H1) can be verified. As we can see in the tables, except for the coefficient of DCFO $*$ CFO in model (3) which does not conform to the prediction, the positive and negative signs of other variables all meet the expectations, which can prove that conservatism exists in the listed financial companies. Table 5 reports the regression results to test $(\mathrm{H} 2)$, and it shows that the coefficient on DCFO * CFO * ICQ is -2.926 $(P<0.01)$, and the coefficient on $\mathrm{D} \Delta \mathrm{NI}_{t-1} * \Delta \mathrm{NI}_{t-1} * \mathrm{ICQ}$ is 7.527, which is not significant; the coefficients of these variables confirm that there is a positive correlation between the quality of internal control and accounting conservatism in financial industry. Table 6 reports the regression results to test (H3) when it replaces ICQ with HLIC. The coefficient of $\mathrm{DCFO} * \mathrm{CFO} * \mathrm{HLIC}$ is $-0.824(P<0.01)$, and the coefficient of $\mathrm{D} \Delta \mathrm{NI}_{t-1} * \Delta \mathrm{NI}_{t-1} * \mathrm{HLIC}$ is 5.511 , which implies that companies which have enhanced their internal control are more conservative; therefore, $(\mathrm{H} 3)$ is true. Furthermore, the control variables do not change the positive and negative directions when we add them in the models one by one, which indicates that allowing for the effect of other important factors, the results of this study are not affected (as space is limited, we do not list the regression results when control variables are literally added). Meanwhile, the results of the accrual-based loss recognition model regression and the persistence of earnings changes model regression basically reach the same conclusion, which can ensure the reliability of the empirical results to some extent.

\section{Conclusion}

We adopt the entropy method to quantify the internal control quality, and then apply two different models to look into the relationship between the internal control quality and accounting conservatism based on the Chinese financial industry samples. The results show that earnings conservatism exists in financial listed companies; and the quality of internal control and accounting conservatism is positively correlated; and companies which have enhanced their internal control are more conservative. These results are consistent with the conclusion in the study of Goh and Li [2], and the relationship between the quality of internal control and conservatism in financial industry shows no difference compared with other industries.

The financial industry is a high-risk industry. The innovative financial instruments and the changing economic environment add to the complexity of the internal control. Accounting conservatism is not only an important evidence for effective internal control system, but also an important feature of earnings quality, which is generally recognized in academics. This study confirms that internal control can improve the accounting conservatism of financial reports, and provides a theoretical framework for us to improve the internal control mechanism in financial enterprises. However, our study also has some limitations. We only include 40 listed financial companies in our sample, whereas many unlisted ones which also play an important role in social economic activities are excluded. Besides, this study takes no further test on the possible endogeneity between internal control and conservatism, and it can be an effort in the future.

\section{Conflict of Interests}

The authors declare that there is no conflict of interests regarding the publication of this paper.

\section{Acknowledgments}

This research described in this paper was substantially supported by a Program (no. NCET-11-0524) for New Century Excellent Talents in University, Grants (no. 71371194, 71171201, and 71221006) from the National Natural Science Foundation 
of China, and a Project (no. 2011JQ025) from the National Basic Research Program of China.

\section{References}

[1] R. L. Watts, "Conservatism in accounting. Part I: explanations and implications," Accounting Horizons, vol. 17, no. 3, pp. 207221, 2003.

[2] B. W. Goh and D. Li, "Internal controls and conditional conservatism," Accounting Review, vol. 86, no. 3, pp. 975-1005, 2011.

[3] V. Munsif, K. Raghunandan, D. V. Rama, and M. Singhvi, "Audit fees after remediation of internal control weaknesses," Accounting Horizons, vol. 25, no. 1, pp. 87-105, 2011.

[4] J. S. Hammersley, L. A. Myers, and C. Shakespeare, "Market reactions to the disclosure of internal control weaknesses and to the characteristics of those weaknesses under section 302 of the Sarbanes Oxley Act of 2002," Review of Accounting Studies, vol. 13, no. 1, pp. 141-165, 2008.

[5] J. Doyle, W. Ge, and S. McVay, "Determinants of weaknesses in internal control over financial reporting," Journal of Accounting and Economics, vol. 44, no. 1-2, pp. 193-223, 2007.

[6] M. Ogneva, K. R. Subramanyam, and K. Raghunandan, "Internal control weakness and cost of equity: evidence from SOX section 404 disclosures," Accounting Review, vol. 82, no. 5, pp. 1255-1297, 2007.

[7] G. Q. Zhang, "Internal control and earnings quality: the empirical evidences based on A-share companies in 2007," Economic Management, vol. 30, no. 23-24, pp. 112-119, 2008 (Chinese).

[8] B. I. Qi, T. Gaoliang, and L. Liuchuang, "Internal control deficiencies of listed companies and quality of financial information," Journal of Management Science, vol. 23, no. 4, pp. 3847, 2010 (Chinese).

[9] F. F. Kong, "The deficiency of internal control and the cost of debt: a study based on the perspective of financial information quality," Journal of Guangdong University of Business Studies, no. 3, pp. 75-82, 2012 (Chinese).

[10] D. Givoly, C. K. Hayn, and S. P. Katz, "Does public ownership of equity improve earnings quality?" Accounting Review, vol. 85, no. 1 , pp. 195-225, 2010

[11] X. G. Guo, "Entropy method and application to the comprehensive evaluation," The Study of Finance and Economics, vol. 5, no. 6, pp. 22-24, 1994 (Chinese).

[12] F. H. Wen, Z. Li, C. H. Xie, and S. David, "Study on the fractal and chaotic features of the Shanghai composite index," FractalsComplex Geometry Patterns and Scaling in Nature and Society, vol. 20, no. 2, pp. 133-140, 2012.

[13] C. S. Armstrong, W. R. Guay, and J. P. Weber, "The role of information and financial reporting in corporate governance and debt contracting," Journal of Accounting and Economics, vol. 50, no. 2-3, pp. 179-234, 2010.

[14] H. Ashbaugh-Skaife, D. W. Collins, and W. R. Kinney Jr., "The discovery and reporting of internal control deficiencies prior to SOX-mandated audits," Journal of Accounting and Economics, vol. 44, no. 1-2, pp. 166-192, 2007.

[15] A. Levitt, "The numbers game: Remarks delivered at the NYU Center for Law and Business," New York, NY, USA, 1998.

[16] S. H. Penman and X.-J. Zhang, "Accounting conservatism, the quality of earnings, and stock returns," Accounting Review, vol. 77, no. 2, pp. 237-264, 2002.

[17] M. C. Jensen, "The modern industrial revolution, exit, and the failure of internal control systems," The Journal of Finance, vol. 48, no. 3, pp. $831-880,1993$.
[18] Z. G. Zhang, Y. L. Liu, and G. Q. Li, "Comparison and choice of accounting conservatism measurement method-empirical research on relevance and reliability," Accounting Research, no. 2, pp. 37-41, 2012 (Chinese).

[19] R. Ball and L. Shivakumar, "Earnings quality in UK private firms: comparative loss recognition timeliness," Journal of Accounting and Economics, vol. 39, no. 1, pp. 83-128, 2005.

[20] S. Basu, "The conservatism principle and the asymmetric timeliness of earnings," Journal of Accounting and Economics, vol. 24, no. 1, pp. 3-37, 1997.

[21] M. H. Liu, "Assurance engagement of internal control: controversy and choice," Accounting Research, no. 9, pp. 43-50, 2010 (Chinese).

[22] Y. H. Yang and W. Wang, "Research on the information disclosure of internal control of Shanghai's list companys in 2006," Accounting Research, no. 3, pp. 35-42, 2008 (Chinese). 


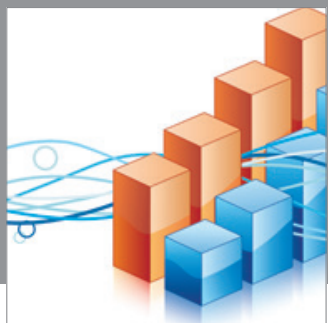

Advances in

Operations Research

mansans

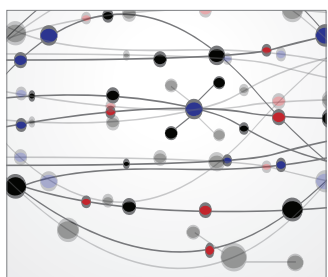

The Scientific World Journal
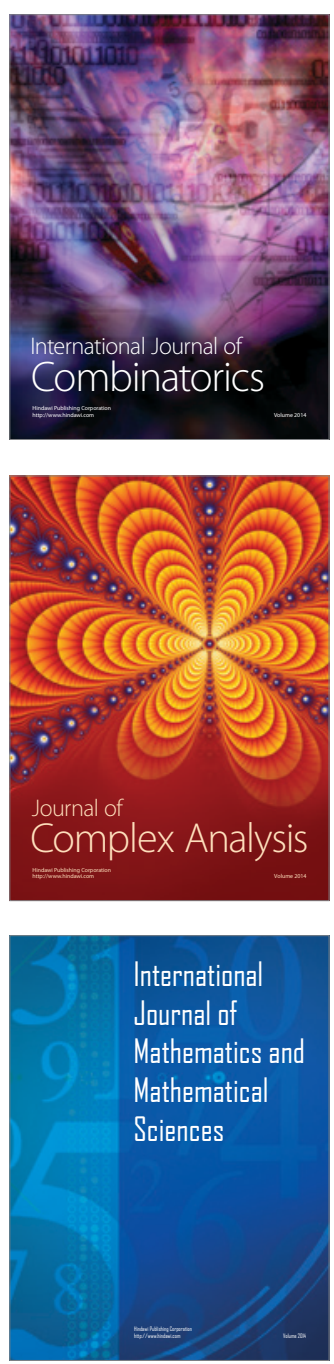
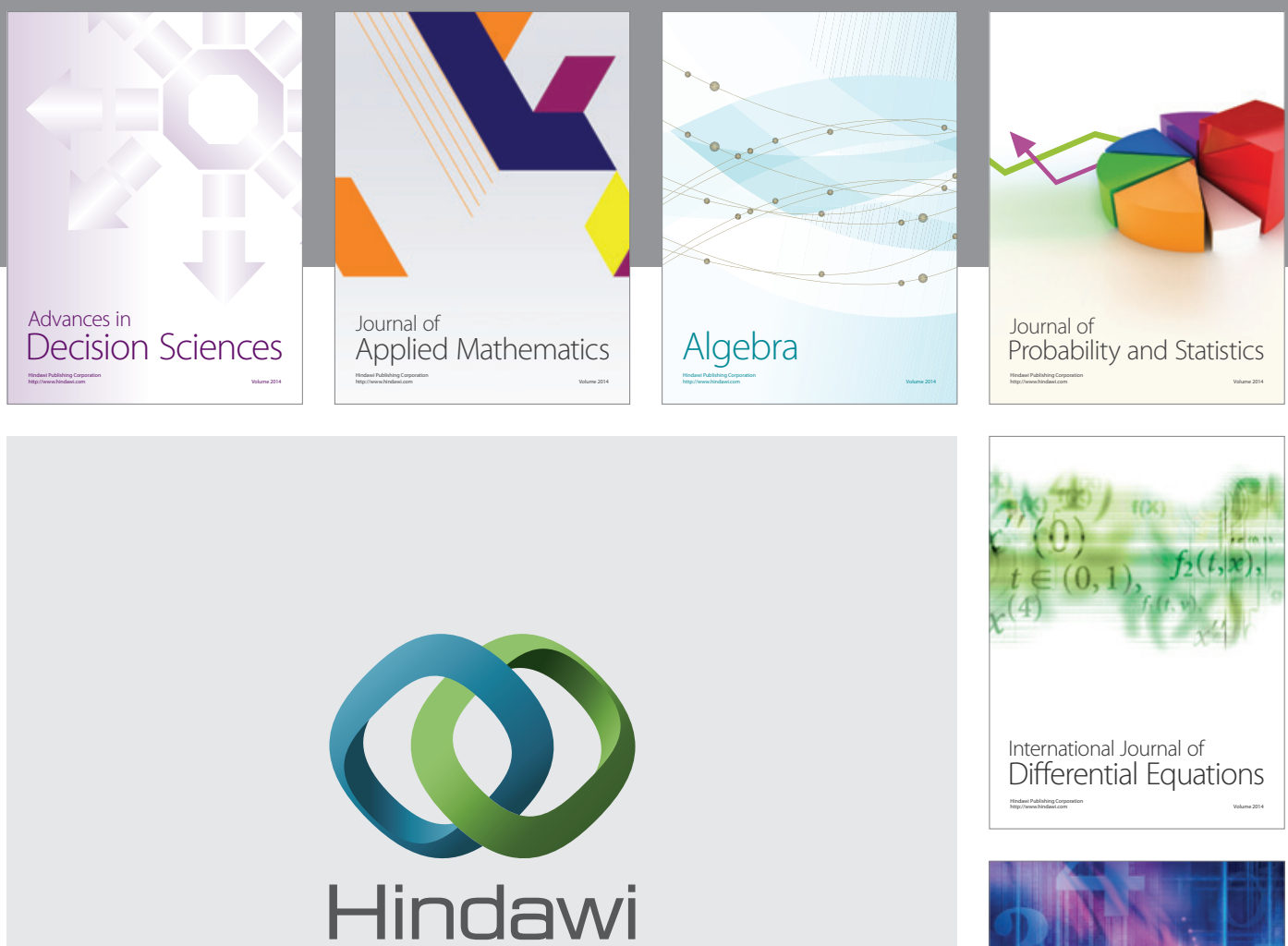

Submit your manuscripts at http://www.hindawi.com
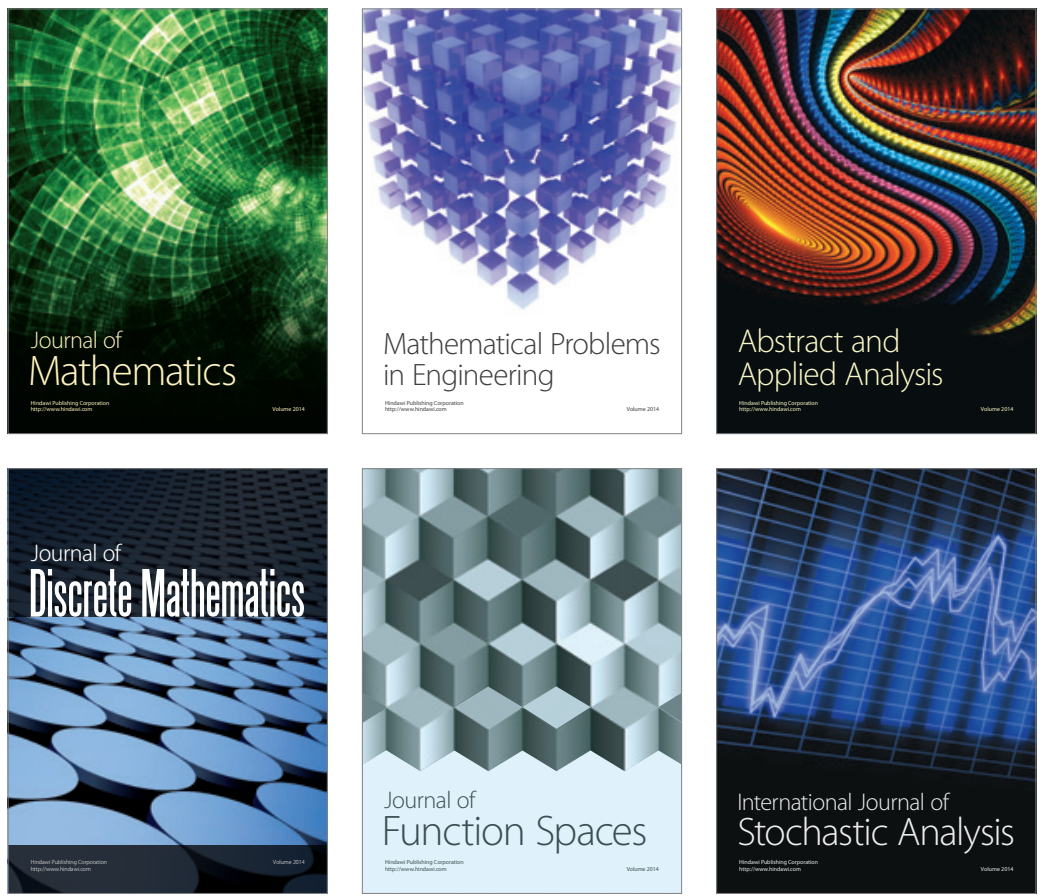

Journal of

Function Spaces

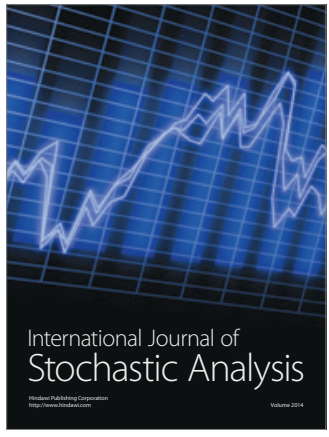

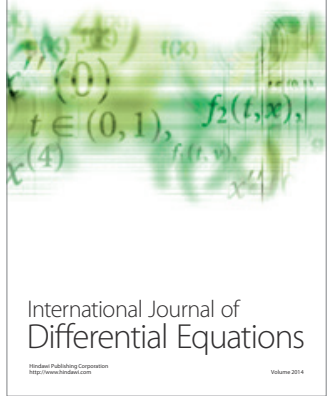
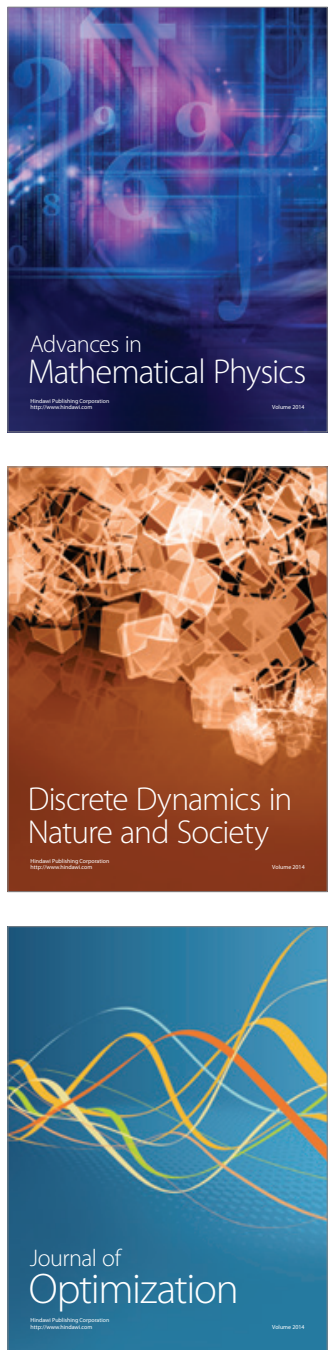